\title{
General practitioners' office consultations with elderly patients - diagnoses and prescriptions: A report from the Møre \& Romsdal Prescription Study
}

\author{
Jørund Straand, MD, Hogne Sandvik, MD, PhD, and Kirsten Rokstad, MD, PhD \\ Division for General Practice, University of Bergen, Norway \\ Correspondence to: Jørund Straand, Division for General Practice, University of Bergen, Ulriksdal 8c, N-5009 Bergen, Norway \\ Telephone +4755586144 telefax +4755586130 E-mail Jorund.Straand@isf.uib.no
}

\begin{abstract}
Study objectives: To analyse office consultations with elderly people in general practice: reason for encounter, diagnostic indications for prescribing drugs, and what drugs are prescribed for the different diagnoses.

Design: Cross-sectional survey.

Setting: The Norwegian county of Møre and Romsdal.

Participants: In 1988 and 1989 the general practitioners recorded all encounters with patients over a period of two months. The participation rate was close to $100 \%$, and we report data from 10,850 office consultations with elderly patients (65 years and older).

Main results: $60 \%$ of the consultations involved female patients, mean age was 74 years. One of three consultations were for new diagnoses, two thirds were follow-ups. The most common diagnostic groups were cardiovascular (28\%), musculoskeletal (13\%), psychiatric (8\%) and respiratory diseases (8\%). Almost $10 \%$ of all consultations were for hypertension. Drugs were prescribed during $56 \%$ of all consultations. $27 \%$ of all prescriptions were for cardiovascular drugs, and $25 \%$ were for the central nervous system. The 20 most common diagnoses constituted more than half of all the diagnoses, and the ten most common drugs (therapeutic groups) constituted almost $70 \%$ of all prescriptions.

Conclusion: In the context of quality assurance large benefits may be gained even if focus is put on rather few diagnoses and drugs.
\end{abstract}

Key words: health services for the aged; family practice; drugs

This paper is based on a previous Norwegian publication: Straand J, Sandvik H, Rokstad K. 10850 kontorkonsultasjoner med eldre pasienter i allmennpraksis. Fra diagnose-resept-undersøkelsen i Møre og Romsdal. Tidsskr Nor Lageforen 1997; 117: 3980-3984. With permission.

\section{INTRODUCTION}

Elderly people usually suffer from more diseases than young people. Likewise, they use more drugs (1-3), and are more prone to drug related problems (polypharmacy, interactions, side effects) that may complicate their clinical condition further (3-6).

General practitioners (GPs) prescribe most of the drugs taken by elderly people. Drugs are issued in almost six out of ten contacts with the GP, more often for women than for men, and more often with increasing age of the patient (7).

Most of the pharmacoepidemiological surveys in Norway have been performed without diagnostic data, making it difficult to evaluate the quality of the prescriptions. We have performed a survey where it is possible to relate the diagnosis (indication for prescribing) to the drug actually prescribed for the individual patient.

Most contacts in general practice take place in the doctor's surgery $(8,9)$. In this paper we have analysed such contacts with elderly people: main reason for contact, indications for prescribing drugs, and what drugs are prescribed for the different diagnoses.

\section{METHODS}

This is a report from the Møre \& Romsdal Prescription Study (MRPS), in which almost all GPs in the Norwegian county of Møre \& Romsdal recorded their contacts with patients and prescriptions during November 1988 and November 1989.

Two separate periods were chosen for the survey because between the two periods an intervention study 
was conducted on improving the GPs' prescription patterns (for insomnia and acute cystitis) by prescribing feedback and therapeutic recommendations sent them by mail (10).

During the survey the GPs used a specially designed prescription form, one part of which was handed to the patients as their prescription sheet. A carbon copy was retained with a questionnaire. On this the GPs filled in information about:

- The patients' age and sex

- Type of GP-patient contact (office consultation, home visit, telephone consultations, or indirect contact through the receptionist)

- Whether the contact was initial or follow-up for the diagnosis

- Reason for encounter, and diagnostic indication(s) for the prescriptions

- Prescription information, and whether the prescription was a first time or repeat one

Several drugs could be issued on the same prescription sheet during the same ordination. The questionnaires were completed during all contacts irrespective of drugs were issued or not.

The twelve pharmacies in the county kept a record every time a GP used his or her own personal prescription form instead of the form designed for the study. This showed that other forms were used in less than $0.5 \%$ of the prescriptions (10).

The GPs were provided with a list of about 250 of the most common diagnoses used in general practice in terms of The International Classification of Primary Care (ICPC). The GPs were not obliged to use specific diagnostic criteria. During the coding we modified the ICPC-list: in some cases, different codes that covered similar clinical conditions (e.g., hypertension and elevated blood pressure) were grouped together as can be read from the tables.

The drugs were classified according to the Anatomical Therapeutic Chemical (ATC) classification. In 1988, 752 different drugs were listed in the Pharmaceutical Industry's Catalogue in Norway.

The following age categories were used: younger olds (65-74 years), and older olds (75+).

\section{MATERIAL}

Of the 156 GPs in the county, 149 (95.5\%) participated in the MRPS during the first period. The participation rate rose to $98 \%$ during the second period. During the MRPS the GPs altogether recorded 90,458 contacts with patients during which 74,079 drug prescriptions were issued. Of all the contacts, 21,512 were with patients aged 65 years or more, and about half of them $(10,850)$ were office consultations. During the 10,850 consultations, 9,521 drug prescriptions were issued.
The 10,850 office consultations and the 9,521 prescriptions constitute the material for this article.

\section{RESULTS}

Of the 10,850 office consultations, $60 \%$ were with female patients. The mean age of the patients was 74 years, $58 \%$ of all were younger olds (Figure 1). Two of three of the consultations were for diagnoses established previously, while every third consultation was for a new problem. Most of the consultations took place on the five weekdays with most consultations on Tuesdays (23\%) and the least on Fridays (16\%). Only $1.2 \%$ of the office consultations were performed during weekends.

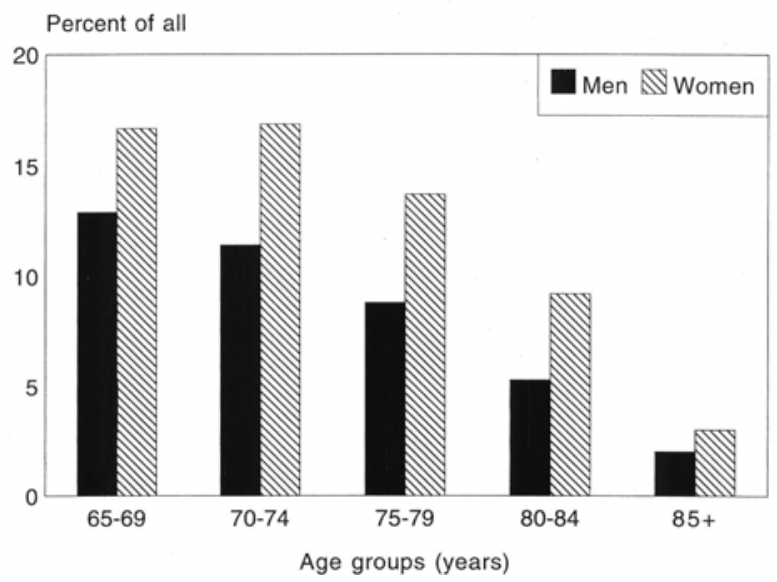

Figure 1. Elderly patients (65+) consulting general practitioners in their surgeries, by patients' sex and age groups.

The most common reasons for visiting the GPs' surgeries were diagnoses in the cardiovascular system (ICPC-group K; 28\%), followed by the musculoskeletal group (ICPC-group L; 13\%), psychiatric problems (ICPC-group P; 8\%), and respiratory tract illnesses (ICPC-group R; 8\%). The 20 most commonly recorded diagnoses for seeing the GP comprised more than half of all diagnoses (Table 1). A little less than one in ten consultations were for hypertension, more commonly for females and for the younger olds (Table 1).

The GPs prescribed one or more drugs during $56 \%$ of all office consultations. The proportion of the consultations during which drug treatment was issued, varied with the diagnoses: from $28 \%$ of the consultations for cerebrovascular stroke, to $99 \%$ of the consultations for insomnia (Table 1). Of the consultations during which drug prescriptions not were issued, $47 \%$ of the patients were already taking drugs issued previously, and another $11 \%$ were referred to hospital. 
Table 1. The twenty most commonly recorded diagnoses for seeing elderly patients in the general practitioners' surgeries, by patients' sex and age groups, and the proportions of the consultations for the various diagnoses where drug prescriptions $\left(\mathrm{R}_{\mathrm{x}}\right)$ are issued.

\begin{tabular}{|c|c|c|c|c|c|c|c|c|}
\hline \multirow[b]{2}{*}{ Diagnosis } & \multirow[b]{2}{*}{ ICPC $^{1}$-codes } & \multicolumn{2}{|c|}{$\operatorname{Sex}(\%)$} & \multicolumn{2}{|c|}{ Age groups $(\%)$} & \multirow{2}{*}{$\begin{array}{l}\mathrm{R}_{\mathrm{x}} ? \\
(\%)\end{array}$} & \multicolumn{2}{|l|}{ Total } \\
\hline & & M & $\mathrm{F}$ & $65-74$ & $75+$ & & Numbers & $(\%)$ \\
\hline 1. Hypertension & K85/86/87 & 7.3 & 11.3 & 10.7 & 8.3 & 60 & 1048 & 9.7 \\
\hline 2. Coronary heart disease & K07/74/89/91 & 7.9 & 5.4 & 6.2 & 6.6 & 63 & 691 & 6.4 \\
\hline 3. Diabetes mellitus & T90 & 5.7 & 5.1 & 5.1 & .6 & 39 & 580 & 5.3 \\
\hline 4. Osteo-/arthritis & L88/89/90/91 & 3.0 & 5.2 & 4.0 & 4.7 & 63 & 466 & 4.3 \\
\hline 5. Heart failure & $\mathrm{K} 75 / 77$ & 4.4 & 3.3 & 2.2 & 5.8 & 58 & 407 & 3.7 \\
\hline 6. Insomnia & P07 & 2.8 & 3.7 & 2.9 & 4.0 & 99 & 364 & 3.3 \\
\hline 7. Acute cystitis & U71 & 1.5 & 3.3 & 2.3 & 2.9 & 92 & 279 & 2.6 \\
\hline 8. Anxiety/neurosis & P01/04/74 & 1.0 & 2.9 & 2.2 & 2.0 & 91 & 230 & 2.1 \\
\hline 9. Depression & P02/76 & 1.4 & 2.5 & 2.6 & 1.3 & 73 & 223 & 2.1 \\
\hline 10. Cardiac arrythmias & K04/78/79/80 & 2.1 & 1.4 & 1.9 & 1.5 & 46 & 187 & 1.7 \\
\hline 11. Eczema & S86/87/88 & 1.8 & 1.6 & 1.8 & 1.4 & 90 & 180 & 1.7 \\
\hline 12. Cough and cold & $\mathrm{R} 05 / 07 / 21 / 22 / 23 / 74$ & 1.4 & 1.6 & 1.6 & 1.5 & 75 & 166 & 1.5 \\
\hline 13. Low back pain & L02/03/84/86 & 1.7 & 1.4 & 1.8 & 1.1 & 60 & 164 & 1.5 \\
\hline 14. Acute bronchitis & R76 & 1.7 & 1.3 & 1.5 & 1.5 & 83 & 160 & 1.5 \\
\hline 15. Asthma & R96 & 1.7 & 1.1 & 1.6 & 1.1 & 80 & 149 & 1.4 \\
\hline 16. Anemia & B80/81/82 & 1.5 & 1.0 & 0.8 & 1.8 & 47 & 131 & 1.2 \\
\hline 17. Infect. conjunctivitis & F70 & 1.2 & 1.2 & 1.3 & 1.1 & 95 & 130 & 1.2 \\
\hline 18. Dizziness & N17 & 0.6 & 1.0 & 0.6 & 1.2 & 51 & 93 & 0.9 \\
\hline 19. Pneumonia & R81 & 0.9 & 0.6 & 0.7 & 0.7 & 68 & 77 & 0.7 \\
\hline 20. Cerebrovascular stroke & K90 & 0.9 & 0.4 & 0.7 & 0.5 & 28 & 68 & 0.6 \\
\hline Sum $(\%)(1-20)$ & & 50.5 & 55.3 & 52.5 & 54.6 & & 5793 & 53.4 \\
\hline Other diagnoses $(\%)$ & & 49.4 & 45.2 & 47.5 & 45.4 & & 5057 & 46.6 \\
\hline $\mathrm{N}=(100 \%)$ & & 4390 & 6460 & 6293 & 4557 & & 10850 & \\
\hline
\end{tabular}

${ }^{1}$ International Classification of Primary Care

In Table 2 the 9,521 drug prescriptions are shown distributed according to the main anatomical ATC groups. Twenty-seven percent of the prescriptions were for drugs acting on the cardiovascular system (ATC class C), 25\% were drugs for the central nervous system (ATC class N). Altogether 358 (of 752 possible) different drugs were issued.

The ten ATC therapeutic groups most commonly prescribed, comprised almost $70 \%$ of all (Table 3 ). Following next to the ten theraputic groups listed in the table were: anti-asthmatics (ATC-group R03, $2.6 \%$ ), cough and cold preparations (R05, 2.3\%), psychoanaleptics which here equals antidepressants (N06, 2.0\%), antidiabetic therapy (A10, 2.0\%), and systemic corticosteroids (H02, 1.8\%). More than every sixth prescription were for psycholeptics (ATC-group N05) (Table 3). In this group, benzodiazepines comprised $92 \%$, while the remaining was antipsychotics. In the cardiac therapy group (ATC-group C01;9\%), nitrates comprised $71 \%$, and digitalis preparations $27 \%$. For each of the ten ATC therapeutic groups most frequently prescribed, the three most commonly recorded diagnostic indications comprised between $37 \%$
Table 2. General practitioners' drug prescriptions $\left(R_{x}\right) d u-$ ring office consultations for elderly patients $(65+)$, by the $\mathrm{ATC}^{1}$ system main anatomical classes.

\begin{tabular}{lrr}
\hline & \multicolumn{2}{c}{$\mathrm{R}_{\mathrm{x}}$} \\
\cline { 2 - 3 } ATC system/ Main anatomical classes & $\mathrm{N}=$ & $(\%)$ \\
\hline C: Cardiovascular system & 2593 & 27.2 \\
N: Central nervous system & 2359 & 24.8 \\
J: General systemic antiinfectives & 800 & 8.4 \\
R: Respiratory organs & 760 & 8.0 \\
A: Alimentary tract and metabolism & 696 & 7.3 \\
M: Musculoskeletal system & 658 & 6.9 \\
D: Dermatologicals & 564 & 5.9 \\
S: Sensory organs & 436 & 4.6 \\
H: Systemic hormonal preparations & & \\
$\quad$ excl. sex hormones & 269 & 2.8 \\
B: Blood and bloodforming organs & 187 & 2.0 \\
G: Genitourinary system and sex hormones & 175 & 1.8 \\
$\quad$ Others & 24 & 0.3 \\
\hline SUM $=$ & 24 & 100.0 \\
\hline
\end{tabular}

${ }^{1}$ Anatomical Therapeutic Chemical Classification System

${ }^{2}$ ATC classes L (antineoplastic and immunomodulating agents), P (antiparasitic products), and V (various) 
Table 3. The ten most frequently prescribed drugs (ATC system therapeutic groups) for elderly (65+) patients during office consultations in general practice, and the three most commonly recorded diagnoses (\%) for prescribing in each therapeutic group.

\begin{tabular}{|c|c|c|c|c|c|c|c|c|c|}
\hline \multirow[b]{2}{*}{$\begin{array}{l}\text { ATC } \\
\text { code }\end{array}$} & \multirow[b]{2}{*}{ Therapeutic group } & \multirow[b]{2}{*}{$\begin{array}{c}\% \text { of } \\
\text { all }\end{array}$} & \multicolumn{6}{|c|}{ The three most commonly recorded diagnoses for prescribing $(\%)$} & \multirow[b]{2}{*}{$\begin{array}{r}\text { Diagnoses } \\
(1+2+3) \% \\
\text { of all }\end{array}$} \\
\hline & & & No. 1 diagnosis & $(\%)$ & No. 2 diagnosis & $(\%)$ & No. 3 diagnosis & $(\%)$ & \\
\hline N05 & Psycholeptics & 17.1 & Insomnia & 50 & Anxiety/neurosis & 27 & Depression & 8 & 85 \\
\hline $\mathrm{C} 01$ & Cardiac therapy & 9.2 & Coronary heart disease & 63 & Heart failure & 19 & Cardiac arrythmias & s 7 & 89 \\
\hline J01 & Antibiotics & 8.4 & Acute cystitis & 32 & Acute bronchitis & 18 & Skin infections & 8 & 58 \\
\hline $\mathrm{C} 03$ & Diuretics & 7.5 & Hypertension & 46 & Heart failure & 37 & Swollen ankles & 5 & 88 \\
\hline $\mathrm{C} 02$ & Antihypertensives & 5.2 & Hypertension & 66 & Coronary heart disease & 15 & Cardiac arrythmias & s 9 & 90 \\
\hline M01 & NSAIDs & 5.1 & Osteo-/arthritis & 52 & Muscle/joint/tend ${ }^{2}$ & 21 & Low back pain & 4 & 77 \\
\hline N02 & Analgesics & 4.8 & Osteo-/arthritis & 18 & Low back pain & 13 & Headache & 6 & 37 \\
\hline D07 & Dermatol. corticosteroids & s 4.1 & Eczema & 64 & Psoriasis & 11 & External otitis & 4 & 79 \\
\hline $\mathrm{C} 07$ & Beta blockers & 4.0 & Hypertension & 48 & Coronary heart disease & 35 & Cardiac arrythmias & s 7 & 90 \\
\hline S01 & Opthalmologicals & 3.8 & Infect.conjunctivitis & 6 & Glaucoma & 2 & Other conjunctiv. ${ }^{3}$ & 7 & 75 \\
\hline \multicolumn{2}{|c|}{ Sum $(\%)$} & 69.2 & & & & & & & \\
\hline \multicolumn{2}{|c|}{ Others $(\%)$} & 30.8 & & & & & & & \\
\hline \multicolumn{2}{|c|}{ Total (\%) } & 100.0 & & & & & & & \\
\hline \multicolumn{2}{|l|}{$\mathrm{N}=$} & 9521 & & & & & & & \\
\hline
\end{tabular}

(analgesics) and $90 \%$ (beta-blockers, antihypertensives) of all (Table 3$)$.

\section{DISCUSSION}

\section{Method}

This work is part of the largest survey of patient contacts ever made in Norway. Its strength is that nearly $100 \%$ of the physicians participated according to protocol.

The study was performed during November 1988 and November 1989. This may have caused some diagnostic bias concerning seasonal diseases.

Another possible source of error is that diagnoses may be used for justifying the prescription of certain drugs. A request for a hypnotic may be the sole basis for a diagnosis of insomnia, which in turn makes it "legitimate" to prescribe a hypnotic drug (11). This may have caused an overreporting of such diagnoses. It was considered impractical to use standardized diagnostic criteria. Although the diagnostic validity thus may be weakened, the diagnoses reported here are probably representative for diagnoses made during everyday general practice in Norway.

In general practice the distribution of diagnoses seems to be quite stable over time $(9,12)$. As for drugs, minor changes occur all the time since new drugs are introduced, while others are withdrawn from the market. The uses of single compounds therefore may have changed considerably since our data were recorded. However, because we only report main anatomi- cal groups and therapeutical subgroups according to the ATC classification, we believe that our results are still relevant.

\section{Results}

In general, approximately $60 \%$ of the patients seen in GPs' surgeries are females (12). The present study shows that this holds true also for elderly patients. Even if this is a survey of reasons for contact and not a prevalence study, the results are not very different from prevalence studies reported from Sweden and Denmark $(2,3,13,14)$. Generally, hypertension and heart diseases are the most common problems. Women tend to be given a diagnosis of hypertension more often than men. We found that men more often suffer from coronary heart disease, arrythmias, and heart failure. This finding is in accordance with a systematic health survey among elderly people in Northern Sweden (13).

The data reported here were recorded before the new generation of antidepressant drugs (i.e. the selective serotonin reuptake inhibitors) was launched. Today prescriptions for antidepressants therefore probably constitute a larger share than the $2 \%$ reported here.

At the time when the survey was performed GPs had a conservative attitude towards treating hypertension in the elderly. According to later recommendations, more elderly hypertensive men should probably have been treated (15). We can only speculate whether this would have prevented the development of heart diseases in this population. 
We found that drugs were prescribed during $56 \%$ of all consultations. Another $21 \%$ had previously received one or more prescriptions for the same diagnosis. Thus, it seems that altogether $77 \%$ of elderly people receive drug treatment for their reason for visiting their GP. Other studies have revealed similar numbers $(1,3,16,17)$. The most commonly prescribed drugs for elderly people are cardiovascular drugs, psychotropic drugs, and analgesics, a finding also reported by others $(1-3,16,17)$.

The patients do not always know why they are taking their drugs, and this problem increases by increasing age (1). Other studies have revealed that many drugs prescribed to elderly people are given for questionable indications, and that the treatment is inadequately followed up $(1,4,5,18)$. This problem also tends to get worse in old age $(4,5)$.

Since most elderly people live in their own homes and are responsible for their own medication, it is important that the GPs carefully instruct them how to handle their drugs. Key words are better communication (both spoken and written) in what may be called "patient-centered prescribing" (19): The physician and the patient must cooperate in establishing a shared understanding of the problem, the treatment goals, and also regarding the duration of the treatment.

In the context of quality assurance it is an advantage that so few diagnoses and drugs make up a large proportion of the total: "Common diseases commonly occur, rare diseases rarely happen" (20). Even if we focus on a few diagnoses and drugs, a large impact may be made upon the quality of drug prescribing for the elderly in general practice.

We thank the GPS in Møre and Romsdal who collected the data for this survey.

\section{REFERENCES}

1. Landahl S. Drug treatment in 70-82-year-old persons. A longitudinal study. Acta Med Scand 1987; 221: 17984.

2. Österlind P, Bucht G. Drug consumption during the last decade among persons born in 1902 in Umeå, Sweden. A longitudinal population study. Drugs Aging 1991; 1: 477-86.

3. Cartwright A, Smith C. Elderly people, their medicines, and their doctors. London: Routledge, 1988.

4. Ferguson JA. Patient age as a factor in drug prescribing practices. Can J Aging 1990; 9: 278-95.

5. Tamblyn RM, McLeod PJ, Abrahamowicz M, Monette J, Gayton DC, Berkson L, et al. Questionable prescribing for elderly patients in Quebec. Can Med Assoc J 1994; 150: 1801-9.

6. Wills P, Fastbom J, Claesson CB, Cornelius C, Thorslund M, Winblad B. Use of cardiovascular drugs in an older Swedish population. J Am Geriatr Soc 1996; 44: 54-60.

7. Rokstad K, Straand J, Fugelli P. General practitioners' drug prescribing practice and diagnoses for prescribing: the Møre \& Romsdal prescription study. J Clin Epidemiol 1997; 50: 484-95.

8. Johnsen R, Holtedahl KA. Working hours and productivity of curative services in general practice in 1993. Practice profiles of Norwegian primary physicians [In Norwegian, English summary]. Tidsskr Nor Lageforen 1997; 117: 1489-92.

9. Rutle O. Focus on the patient. An analysis of contacts with the general practitioner [In Norwegian]. Report No 1/1983. Oslo: Unit for Health Services Research, 1983.

10. Rokstad K, Straand J, Fugelli P. Can drug treatment be improved by feedback on prescribing profiles combined with therapeutic recommendations? A prospective, controlled trial in general practice. $J$ Clin Epidemiol 1995; 48: 1061-8.

11. Everitt DE, Avorn J, Baker MW. Clinical decision-making in the evaluation and treatment of insomnia. Am J Med 1990; 89: 357-62.

12. Rokstad K, Straand J, Sandvik H. Patient encounters in general practice. An epidemiological survey in Møre and Romsdal [In Norwegian, English summary]. Tidsskr Nor Laegeforen 1997; 117: 659-64.

13. Österlind P, Löfgren A, Sandman P, Steen B, Winblad B. Health, disorders, and drug consumption in an elderly population in Northern Sweden. Gerontology 1986; 32: 52-9.

14. Holstein BE, Almind G, Due P, Holst E. Self-reported health status and drug use among the elderly [In Danish, English summary]. Ugeskr Laeger 1990; 152: 386-91.

15. Holmen J, Aursnes I, Forsdahl A, Hetlevik I, Hjermann I, Hjort PF, et al. Hypertension. The Norwegian College of General Practitioners' guideline [In Norwegian]. Report No. U 3-1993, Division for health services research. Verdal: Research centre for public health, National Institute of Public Health, 1993. 
16. Jörgensen TM, Isacson DGL, Thorslund M. Prescription drug use among ambulatory elderly in a Swedish municipality. Ann Pharamacother 1993; 27: 1120-5.

17. Hendriksen C, Lund E, Strømgård E. Intake of drugs among elderly people in a Danish municipality, Rødovre. Acta Med Scand 1983; 214: 67-71.

18. Skoog I, Nilsson L, Landahl S, Steen B. Mental disorders and the use of psychotropic drugs in an 85-year-old urban population. Int Psychogeriatr 1993; 5: 33-48.

19. Straand J. Ten theses about prescription and use of hypnotics in general practice. Utposten 1997; 26: 16-20.

20. Fry J. Common diseases: their nature, incidence and care. Lancaster: MTP Press, 1983. 